\title{
DA CONCEPÇÃO PTOLOMAICA DO MUNDO À PERCEPÇÃO DA PAISAGEM DO MUNDO. \\ ... E MIRANDA FEZ ESCOLA...
}

FROM A PTOLOMAIC CONCEPTION OF THE WORLD TOWARD A LANDSCAPE PERCEPTION OF THE WORLD. ... AND MIRANDA BUILT A METHOD

OF TEACHING LANDSCAPE ARCHITECTURE...

Emmanuel Antonio dos Santos

Professor doutor da UNIVAP, ITA.

E-mail:emmanuel_santos@uol.com.br 


\section{RESUMO}

A modificação na percepção da paisagem, desde a instância planetária até a dimensão local do entorno imediato, cobra necessariamente, no mundo contemporâneo, para além de uma mudança foco, a percepção em múltiplas e diversas escalas, procedimento a que se costuma denominar de interação escalar.

No âmbito mais estrito e paradoxalmente mais abrangente da percepção e do trabalho com a paisagem na pesquisa acadêmica e na docência, nesse novo contexto, destaca-se o trabalho desenvolvido pela professora Miranda Magnoli. Figura de proa e catalisadora dos esforços em constituir no GDPA, desde meados dos anos de 1970 com um pequeno grupo de professores, as linhas de pesquisa e ensino mais avançadas do paisagismo no Brasil. Essas pesquisas viriam mudar as então concepções reducionistas, de paisagem entendida tão-somente como o jardim e do ambiente como o estudo do equilíbrio das espécies.

\section{Palavras-chave: Paisagem, ensino, pesquisa.}

\section{ABSTRACT}

The distinguished perception of the landscape from the planetary dimension trough the local one, charges in the contemporary world mare than a focuses changing point of view the perception in multi and diverse, what we usually call scale interaction.

In the more strict sense and as a paradox more wide way of perception and works with the landscape, both in academic research and on teaching, in this new context is due to the remarkable job developed by professor Miranda Magnoli, strong and wide efforts on funding in the GDPA group, since the 1970, with a small group of teachers the most avant guard research lines on landscape in Brazil. These researches came out to change the so on reductionisms views and understanding of landscape as mostly the gardening and the environment as the study of the species.

\section{Key words: Landscape, teaching, research.}




\title{
DA CONCEPÇÃO PTOLOMAICA DO MUNDO À PERCEPÇÃO DA PAISAGEM DO MUNDO. \\ ... E MIRANDA FEZ ESCOLA...
}

\author{
FROM A PTOLOMAIC CONCEPTION OF THE WORLD \\ TOWARD A LANDSCAPE PERCEPTION OF THE WORLD. \\ ... AND MIRANDA BUILT A METHOD OF TEACHING \\ LANDSCAPE ARCHITECTURE...
}

A concepção ptolomaica de universo, onde os movimentos dos planetas se organizavam em uma mecânica celeste tomando como centro o planeta Terra, foi aceita durante 14 séculos até ser desmentida pelas teorias de Copérnico e Galileu.

Baseado nas idéias de Hiparco, Ptolomeu adotou o sistema geocêntrico, que situa a Terra no centro do universo e, girando em torno dela, Mercúrio, Vênus, a Lua, o Sol, Marte, Júpiter, Saturno e as estrelas. Todos esses astros descreveriam, em suas órbitas, círculos perfeitos, conforme ensinavam Platão e Aristóteles. Essa concepção foi adotada pelos teólogos medievais, os quais rejeitavam qualquer teoria que não colocasse a Terra em lugar privilegiado.

Personalidade das mais célebres da época do imperador Marco Aurélio, Ptolomeu foi o último dos grandes sábios gregos e procurou sintetizar o trabalho de seus predecessores. Por meio de suas obras de astronomia, matemática, geometria, física e geografia, a civilização medieval teve profícuo contato com a ciência grega. Em sua obra Geographike hyphegesis - Introdução à geografia Ptolomeu apresenta as idéias que a Ásia se estendia muito mais a leste, levando Colombo a acreditar ser possível alcançar este continente, se viajasse sempre para oeste, e da existência de um continente ao sul do oceano Índico, afinal confirmada em 1775, quando o capitão James Cook retornou de sua viagem pelo hemisfério sul.

Seu tratado geográfico, apesar do reconhecimento como documento histórico e de constituir-se em obra seminal, apresenta, no entanto, algumas falhas, como contradições entre mapas e textos, e omite informações sobre clima, habitantes e aspectos naturais das terras que descreve.

"Ptolomeu criou as bases desse mapa em Alexandria, por isso os detalhes do Mediterrâneo Oriental são mais próximos da realidade. Há somente três continentes, Europa, Ásia e África; a linha do Equador foi assinalada. As cabeças em torno do mapa representam os grandes ventos. "1

Desde sempre, no entanto, antes mesmo do esforço de síntese empreendido por Ptolomeu, a busca pela compreensão do universo e de sua estruturação, assim como da constituição de suas partes e particularidades componentes, foi e tem sido preocupação da humanidade. $\bigcirc$ desejo de explicar e representar os "lugares que habitamos", suas configurações e sua organização, é próprio da curiosidade e da capacidade de engendramento que nos caracteriza como espécie. 


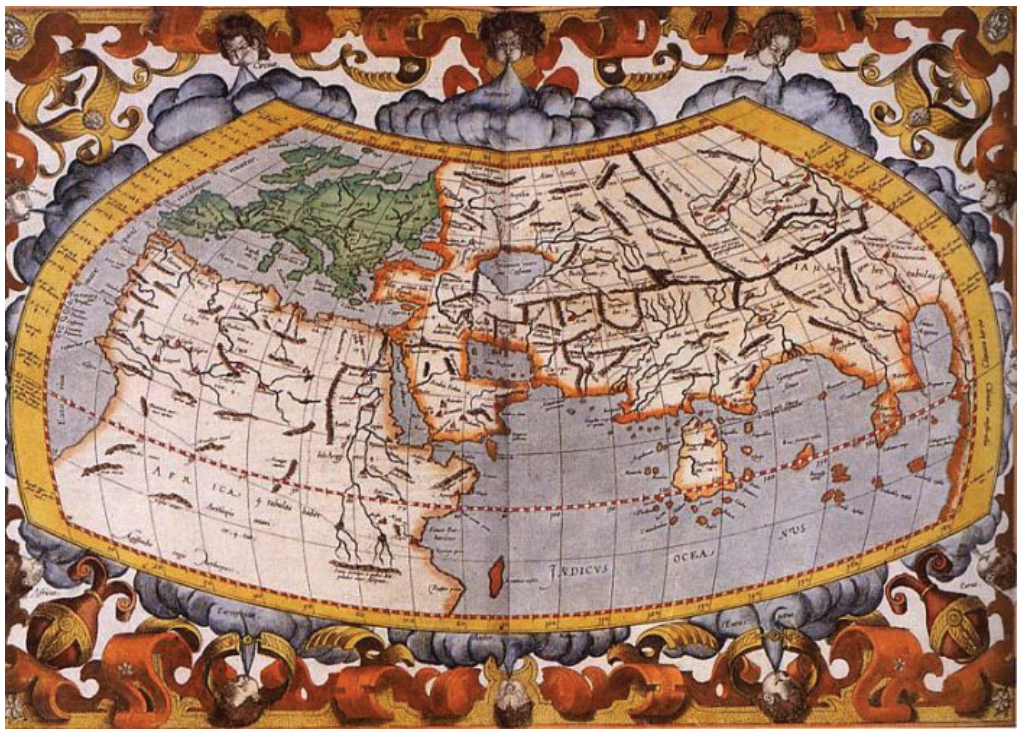

Mapa-múndi desenhado em 1482 a partir das tabelas do tratado Introdução à geografia, de Cláudio Ptolomeu, escrito em 150/170

Fonte: School of Mathematics and Statistics, History of Mathematics, site: greciantiga.org.map

Precisamos, a nós é imprescindível, que nos façamos perceber e entender sempre em correlações, isto é, ser em relação a outrem e ser em relação a algum lugar. Daí a urgência em apreender onde e como estamos, e quais os elementos que nos são caros, imprescindíveis e necessários, tanto para a sobrevivência material quanto espiritual.

Os aspectos relacionados às bases naturais, nas quais a vida se assenta e desenvolve-se, onde se processam os intrincados modos e meios de existência criando e recriando as configurações de nossas formações socioespaciais, vêm sendo, a cada nova investida da humanidade, reprocessados em profundas transformações em que se pode identificar a preponderância histórica, hoje cada vez mais frágil, dos elementos construídos. Mudanças de enfoque em prol de uma apropriação das bases naturais, ainda que desigual em sua acessibilidade e ganhos, em que a cautela para com a sua esgotabilidade inicia a preponderar, já são perceptíveis. Vozes e ecos de uma preocupação com a extinção da espécie, ecos e vozes de uma preocupação estética espiritual, ecos da percepção de um planeta finito na imensidão do universo, ptolomaico ou não.

O geocentrismo há muito não explica mais o universo, a geografia ptolomaica, por sua vez, também não mais dá conta em descrever e explicar a terra em suas múltiplas e diversas configurações. Os avanços e descobertas oriundas das grandes navegações, empreitada corajosa, lúcida e necessária da Idade Média, permitiu desvelar formações espaciais em que a natureza exuberante e por vezes inóspita do novo mundo abriu imensas possibilidades, modificando a compreensão das fronteiras do mundo. A Revolução Industrial, por sua vez, impôs o domínio, que pareceu, então, definitivo e irreversível do até então denominado "mundo natural", pondo em destaque a preponderância da produção em um modelo de acumulação a todo e qualquer custo, mesmo que esses não fossem como não são ainda hoje, de todo conhecidos, pondo em xeque a sobrevivência da espécie.

Nesse cenário, tanto a compreensão como a configuração dos espaços de assentamento humano foram gradativa e muitas vezes velozmente se caracterizando como preponderantemente urbanos, tanto no sentido do senso comum de sinônimo de construído, processado, quanto em seu sentido mais abrangente, como o lugar da urbanidade do modo de vida citadino, civilizado, domesticado e, em alguns casos, cordato.

Seja qual for a acepção a adotar-se e enfatizar-se, importa sobretudo que, de uma maneira geral, os espaços de assentamento humano, a cidade, como lugar de produção e reprodução configuram-se como o ambiente construído, no qual se encobre e perdem-se partes do natu- 
ral, partes das paisagens, empobrecendo o olhar, empobrecendo vivências e a fruição estética ambiental.

"O declínio de muitas cidades antigas é agora creditado tanto às forças geológicas quanto as sociais: à sedimentação e salinização dos solos; aos repetidos terremotos, deslizamentos e afundamentos; ao esgotamento de recursos. Na construção e manutenção de cidades, os seres humanos assumiram um papel dominante como agentes geológicos. A topografia das cidades é constantemente modificada. Colinas são niveladas, baixios aterrados, cursos d água degradados."2

Nesse último caso, de modo equivocado e prematuro, é muito comum pensar, ingenuamente, que cabe ao paisagista, ao arquiteto paisagista, o desenho mitigador, o qual é, no mais das vezes, revelador, no sentido de velar de novo por dissimulação, das condições adversas existentes, seja quanto a conforto ambiental em seu sentido mais amplo, quanto a estética, ou mesmo ecológico, como se as condições adversas fossem preexistentes e não como de fato o são, fruto da apropriação humana para a produção do ambiente construído.

"Os problemas ambientais dizem respeito as formas pelas quais o homem produz seu lugar no espaço como objetivo de garantir suas condições de sobrevivência. Ao produzir o espaço urbano, a sociedade se apropria da natureza e a transforma, e os produtos resultantes dessa transformação tornam-se problemas, demonstrando as contradições desse processo de produção. O entendimento da questão passa, portanto, pela compreensão da complexidade do processo de apropriação, produção e consumo do espaço, que é um processo de produção e reprodução das relações sócio-espaciais e, apesar de a cidade ser o produto da forma de apropriação da natureza pela sociedade, quando se trata de analisar o padrão de urbanização em geral, a natureza está oculta, pois é geralmente vista como a antítese da atividade produtiva humana. "3

O âmbito e a complexidade da compreensão de mundo advindos de pós-revoluções científicas em fins da Idade Média, e mais profundamente pós-Revolução Industrial, dos avanços dos pósguerras, da complexidade da sociedade em rede de informações cada vez mais abrangente, da visibilidade do planeta como território sem fronteiras que as viagens ao cosmos permitiram, provocam, por sua vez, uma profunda modificação na percepção da paisagem do mundo.

Essa modificação na percepção da paisagem, desde a instância planetária até a dimensão local do entorno imediato, cobra necessariamente, no mundo contemporâneo, para além de uma de mudança de foco, a percepção em múltiplas e diversas escalas, procedimento a que se costuma denominar de interação escalar.

No âmbito mais estrito e paradoxalmente mais abrangente da percepção e do trabalho com a paisagem na pesquisa acadêmica e na docência, nesse novo contexto, fui conduzido pela professora Miranda Magnoli, figura de proa e catalisadora dos esforços em constituir no GDPA, desde meados dos anos de 1970 com um pequeno grupo de professores, as linhas de pesquisa e ensino mais avançadas do paisagismo no Brasil, essas pesquisas viriam mudar as então concepções reducionistas, de paisagem entendida tão-somente como o jardim e do ambiente como o estudo do equilíbrio das espécies.

Desse modo posso dizer que a professora Miranda funda a compreensão da paisagem e do ambiente em múltiplas e diversas dimensões, possível somente porque, para produzir conhecimento consistente, responsável e questionador, como cabe ao docente que ensina aprendendo e aprende ensinando em constante troca e reciprocidade, ela parte do questionamento da concepção ptolomaica de mundo para perseguir e atingir uma percepção da paisagem do mundo, não descartando a priori hipóteses, formas e maneiras de entender o ambiente e paisagem, alertando sempre que a paisagem e a atividade de paisagismo se constituem em diversas e múltiplas escalas, desde o paisagismo na escala do entorno imediato e da seleção dos elementos vegetais para a composição dos jardins, até os processos de construção humana dos ambientes de vivência com seus diversos níveis de impactos. 
Amplia-se assim, a partir do GDPA, sempre com Miranda à frente, a idéia de paisagem e ambiente como instâncias mais do que associadas e indissolúveis, imbricadas, interdependentes e as quais requerem mais do que paradigmas próprios, procedimentos mais adequados ao seu entendimento e para a intervenção em seus processos constituintes e de apropriação. É da preocupação com a apropriação franca que se desenvolvem pesquisas e trabalhos relativos aos espaços públicos livres coletivos urbanos, dimensão de compreensão do espaço urbano de uso público na qual se coloca a tarefa de estudar, entender e projetar, mais do que as áreas verdes de embelezamento e "respiro", os espaços para o exercício da cidadania plena, bela sim, contanto que para todos e com todos.

A inserção da área de paisagem e ambiente no âmbito da graduação e da pós-graduação na FAUUSP, campo privilegiado de ensino e pesquisas, vai com o tempo, especialmente pós anos 1980 em diante, como decorrência desse caráter "fundante" o qual Miranda imprime em suas atividades, consolidando a paisagem como dimensão de projeto dos espaços de vivência e da apreensão dos processos de construção do ambiente, tanto no desenvolvimento das atividades de ateliê como na elaboração conceitual, na crítica ao projeto urbano único e irremediável.

Para além da orientação e acompanhamentos formais próprios dos processos da graduação e da pós-graduação, sua influência se refere, sobretudo, aos inúmeros exemplos de dedicação docente, de acolhida generosa, de retidão e firmeza ética, de compromisso com a investigação não se furtando à dúvida, na humildade e curiosidade em aprender juntos e descobrir o novo onde esse parece não mais possível, a inquietação e o não-conformismo com a injustiça socioambiental.

Os esforços em firmar um campo disciplinar do Paisagismo no Brasil, por meio da pesquisa e do ensino, formando docentes, difundindo conceitos, idéias e procedimentos, refletem-se em sua indubitável contribuição para com a formação da consciência e da apreensão da paisagem e do ambiente como dimensões possíveis de um mundo mais justo e mais equilibrado em termos socioambientais.

Não posso deixar de expressar que não tenho dúvidas ser um privilégio privarmos da convivência com Miranda Magnoli, mais do que orientadora, amiga acolhedora, sempre presente com quem compartilhei perceber a paisagem. Creio ser assim, na docência e na pesquisa sem apriorismos, que se faz escola.

\section{Notas}

(1) www.wikcipedia.com.br consulta sobre Ptolomeu em que se pode acessar o mapa utilizado e os esquemas de movimento celeste proposto por Ptolomeu e aceito pela Igreja durante toda a Idade Média.

(2) Curso de extensão em Planejamento Ambiental de áreas urbanas, Prof. Dr. Generoso De Angilis Neto, apud SANTOS, Maria Gercina.

(3) PEREIRA, G. A natureza (dos) nos fatos urbanos: Produção do espaço e degradação ambiental. In: Desenvolvimento e meio ambiente: Cidade e ambiente urbano. Curitiba, PR, Eds. UFPR, 2001, n. 3. 